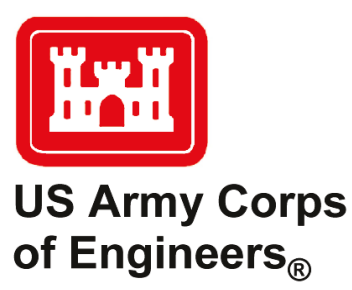

\title{
Initialization and Setup of the Coastal Model Test Bed: CSHORE
}

\author{
by David L. Young, A. Spicer Bak, and Bradley D. Johnson
}

PURPOSE: This Coastal and Hydraulics Engineering Tech Note (CHETN) introduces the application of the cross-shore wave, hydrodynamic, and morphology evolution model CSHORE in the Coastal Model Test Bed (CMTB). Numerical models such as CSHORE are frequently employed by engineers and scientists to investigate various environmental conditions that drive complex coastal morphology evolution at relatively low cost. The CMTB is an initiative to evaluate the strengths and shortcomings in the performance of these coastal numerical models by comparing the model results to high-resolution measurements at the Coastal and Hydraulics Laboratory (CHL), Field Research Facility (FRF), in Duck, NC (Bak et al. 2017). CSHORE is a one-dimensional (1D) numerical model including waves, currents, and bed evolution in the nearshore (Johnson et al. 2012; Kobayashi 2013); this document lays out the model's current setup and configuration as part of the CMTB.

BACKGROUND: Research into nearshore coastal processes is aimed at understanding the physics governing waves and currents, sediment transport, and the resulting morphological change. Predictive nearshore hydrodynamic and morphologic models incorporate these processes to help scientists and engineers solve practical problems involving more intricate natural systems in a cost-effective manner. The CHL FRF has collected nearshore data for over 35 years, and this extensive and sustained data collection effort has proven instrumental in advancing the understanding of nearshore processes. New knowledge regarding the physics of nearshore hydrodynamics and sediment transport directly resulting from observations at the CHL FRF have been incorporated into numerous coastal numerical models (Ruessink et al. 2001; Sheremet et al. 2016; Safak et al. 2017). Observational data relevant to nearshore models collected at the CHL FRF include wave, water level, nearshore current, bathymetry, and meteorological data. These measurements provide an opportunity to systematically evaluate the strengths and weaknesses of various coastal models. The CMTB is a platform for evaluating and testing numerical models used by the U.S. Army Corps of Engineers (USACE) Districts, ERDC (Bak et al. 2017), and the nearshore scientific community. The models are set up to run and evaluate in near real-time in the data-rich environment of the CHL FRF, with access to extensive data that simplify model initialization. Dedicated computational resources are allocated for testing alternative model setups. The CMTB is developed in Python 2.7, and the open-source architecture operates on most operating systems without purchasing expensive licenses, allowing for collaborative development across various institutions. Analysis of the various models implemented in the CMTB will allow systemic quantification of the models' errors as well as the uncertainties in the models' assumptions. CSHORE is the second model included in the CMTB, following the nearshore wave transformation model STWAVE (Massey et al. 2011; Bak et al. 2017). 
CSHORE OVERVIEW: CSHORE is a 1D profile evolution model designed to predict waves, currents, and bed-evolution in the nearshore. The CSHORE model is briefly summarized herein (see Johnson et al. [2012] for more detail). The CSHORE domain assumes a shore-perpendicular (cross-shore) transect with uniform grid spacing, with the origin offshore $(\mathrm{x}=0)$ and positively increasing with distance onshore (Figure 1). A foundational assumption of CSHORE is alongshore uniformity, although obliquely incident waves and longshore currents are included. The governing equations are a combination of the time-averaged, depth-integrated continuity, cross-shore and alongshore momentum, wave action, and roller energy equations. The bed shear stresses in the momentum equations are modeled with a quadratic friction formulation, including a user-entered friction coefficient $\left(\mathrm{C}_{\mathrm{d}}=0.015\right.$ for simulations presented herein), and the radiation stress terms are estimated with linear progressive wave theory (Dean and Dalrymple 1991). The model neglects wave reflection and is configured in the CMTB to neglect the contribution of wind shear stress to the cross-shore and alongshore momentum. The dissipation in the wave energy equation is modeled using the Battjes and Stive (1985) formula as modified by Kobayashi et al. (2005). The roller energy equation is that of Ruessink et al. (2001) for the case of alongshore uniformity, where the roller dissipation is given by the empirical relationship in Kobayashi et al. (2005). CSHORE models the sediment transport, deposition, and erosion with a combination of the Kobayashi and Johnson (2001) suspended sediment model and the Kobayashi et al. (2008a) bedload transport formula, using the critical Shields parameter to estimate incipient sediment motion (Madsen and Grant 1976). Following Kobayashi et al. (2008b), CSHORE also incorporates empirical formulas to account for irregular wave runup, overtopping, and seepage, as well as a probabilistic model of the intermittently wet/dry zone to predict wave runup and overwash.

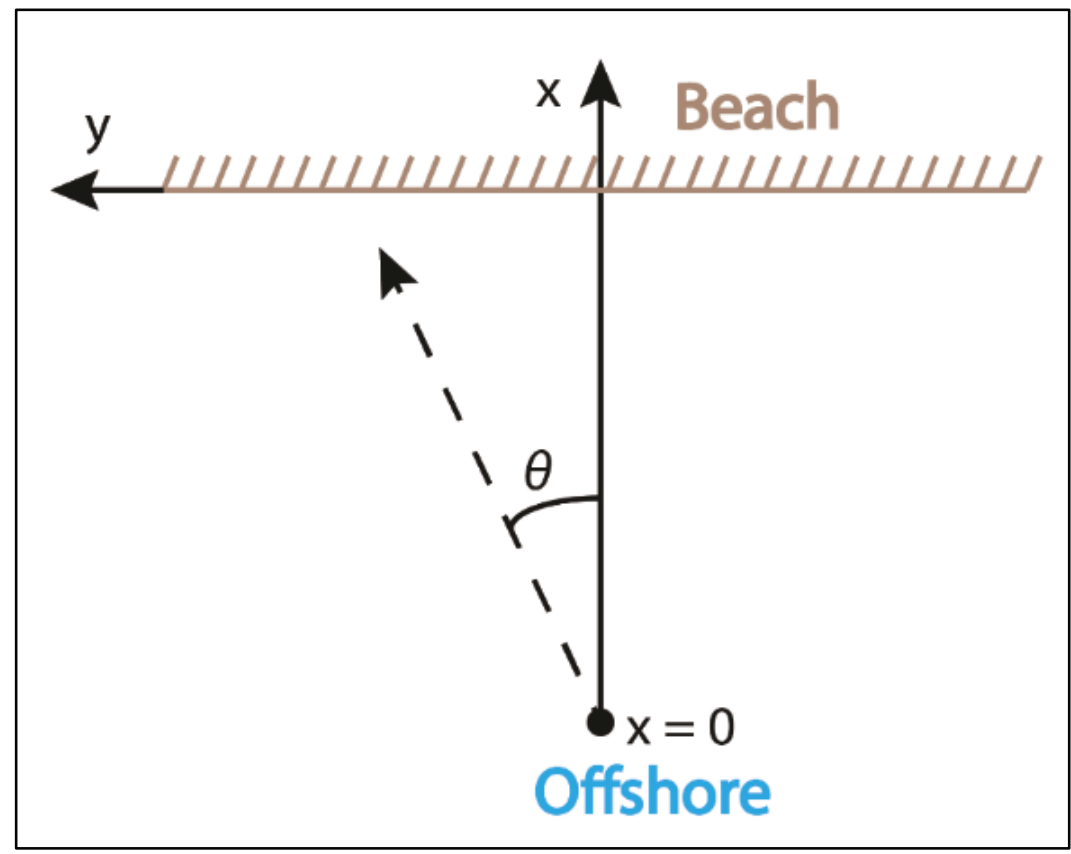

Figure 1. CSHORE computational domain and coordinate system. $\theta$ represents the wave angle at the model boundary. 
CSHORE Model Inputs. Initializing and running a CSHORE model simulation requires an initial bathymetry in the computational domain, as well as wave and water level boundary condition data to force the model. The full list of required physical model inputs is found in Table 1. The input mean water level and initial bed elevations must be in the same datum. To follow established CHL FRF conventions, North American Vertical Datum 1988 (NAVD88) is the datum of choice. Presently, the salinity and temperature inputs are held constant at 30 practical salinity units (psu) and $15{ }^{\circ} \mathrm{C}$.

\begin{tabular}{|c|l|c|}
\hline \multicolumn{2}{|l||}{ Table 1. Required CSHORE model inputs. } & Units \\
\hline \hline Variable Name & \multicolumn{1}{|c|}{ Description } & $\mathrm{m}$ \\
\hline \hline$H_{\mathrm{rms}}$ & $\begin{array}{l}\text { Root-mean-square wave height at the model boundary for each } \\
\text { time-step. }\end{array}$ & $\mathrm{s}$ \\
\hline $\mathrm{T}_{\mathrm{p}}$ & Wave peak period at the model boundary for each time-step. & decimal $^{\circ}$ \\
\hline$\theta$ & $\begin{array}{l}\text { Wave angle at the model boundary for each time step } \\
\text { (see Figure 1). }\end{array}$ & $\mathrm{m}$ (NAVD88) \\
\hline $\mathrm{MWL}$ & Mean water level at the model boundary for each time-step. & $\mathrm{m}$ (NAVD88) \\
\hline $\mathrm{Z}_{\mathrm{b}}$ & Initial bed elevation at each node in the model domain. & $\mathrm{psu}$ \\
\hline Salinity & Single value of water salinity (for entire model duration). & ${ }^{\circ} \mathrm{C}$ \\
\hline Temp & Single value of water temperature (for entire model duration). \\
\hline
\end{tabular}

${ }^{*}$ Measured counter-clockwise positive in model coordinates system (see Figure 1).

CSHORE Model Outputs. CSHORE outputs hydrodynamic (wave, current, water level, runup) and morphological (sediment transport rate, suspended sediment volume, bed elevation) results at the end of each time-step in the model run. A list of the relevant model outputs is found in Table 2. Note that in the CMTB implementation of CSHORE, the value for spatially varied data at dry nodes is set to Not-a-Number (NaN) (IEEE 754 [IEEE 1985]). Additionally, the mean and standard deviation values are output for each time-step (i.e., the mean wave runup-elevation is the mean over the hourly time-step, not the mean over the full model duration).

\begin{tabular}{|c|c|c|}
\hline Variable Name & Description & Units \\
\hline $\mathrm{U}, \mathrm{V}$ & $\begin{array}{l}\text { Depth-integrated mean cross-shore/alongshore current at each } \\
\text { node. }\end{array}$ & $\mathrm{m} / \mathrm{s}$ \\
\hline$\sigma_{\mathrm{u}}, \sigma_{\mathrm{v}}$ & $\begin{array}{l}\text { Standard deviation of the depth-integrated cross-shore/alongshore } \\
\text { current at each node. }\end{array}$ & $\mathrm{m} / \mathrm{s}$ \\
\hline$\sigma_{\text {eta }}$ & Standard deviation of free surface at each node. & $\mathrm{m}$ \\
\hline$\theta$ & Wave angle at each node (see Figure 1). & decimal ${ }^{\circ}$ \\
\hline MWL & Mean water level at each node. & m (NAVD88) \\
\hline $2 \%$ Run-up & $2 \%$ exceedance wave run-up elevation. & m (NAVD88) \\
\hline Mean Run-up & Mean wave run-up elevation. & m (NAVD88) \\
\hline$q_{b x}, q_{b y}$ & $\begin{array}{l}\text { Cross-shore/alongshore bedload sediment transport rate at each } \\
\text { node. }\end{array}$ & $\mathrm{m}^{2} / \mathrm{s}$ \\
\hline$q_{s x}, q_{s y}$ & $\begin{array}{l}\text { Cross-shore/alongshore suspended sediment transport rate at each } \\
\text { node. }\end{array}$ & $\mathrm{m}^{2} / \mathrm{s}$ \\
\hline $\mathrm{V}_{\mathrm{s}}$ & Suspended sediment per unit horizontal bottom area at each node. & $\mathrm{m}^{3} / \mathrm{m}^{2}$ \\
\hline $\mathrm{Zb}$ & Bed elevation at each node. & m (NAVD88) \\
\hline
\end{tabular}


CHL FRF DATA: The data collected at the CHL FRF include wind, barometric pressure, ARGUS imagery (Holman and Stanley 2007), lidar (Brodie et al. 2015), wave (Hanson et al. 2009), current, and water level data spanning the surf zone to the 26-meter (m) bathymetric contour, as well as an extensive bathymetric survey record beginning in 1980. The surveys consist of monthly cross-shore transects of topography and bathymetry spanning the length of the CHL FRF property and extending approximately 1 kilometer offshore, spaced $50 \mathrm{~m}$ apart in the alongshore. This discussion details only those data relevant to CSHORE model runs (see Bak et al. [2017] for a more complete review). Table 3 lists the instruments and corresponding data used in the CSHORE model setup and comparison, including the physical locations of the collecting instruments found in Figure 2. Particularly relevant to profile evolution models are the altimeters, which collect point bed elevations at relatively high sampling rate (albeit irregular temporal intervals). These are used to validate the model's profile evolution at specific locations over the model run or between available surveys. Note that many of the instruments collect additional data not reported in Table 3.

\begin{tabular}{|c|c|c|c|}
\hline Gauge Name & Location & CSHORE-Specific Data & $\begin{array}{l}\text { Reporting } \\
\text { Interval }\end{array}$ \\
\hline End-of-Pier WL & $x=585 m, y=514 m$ & Water level & 6 min. \\
\hline $\begin{array}{l}\text { AWAC8m } \\
\text { AWAC }\end{array}$ & $x=918 m, y=935 m$ & $\begin{array}{l}\text { Significant wave height, peak } \\
\text { frequency, wave angle; directional } \\
\text { depth-averaged currents. }\end{array}$ & $1 \mathrm{hr}$. \\
\hline Array8m Array & $x=914 m, y=825 m$ & See 8 m AWAC. & $1 \mathrm{hr}$. \\
\hline $\begin{array}{l}\text { AWAC6m } \\
\text { AWAC }\end{array}$ & $x=606 m, y=940 m$ & See 8 m AWAC. & $1 \mathrm{hr}$. \\
\hline $\begin{array}{l}\text { AWAC5m } \\
\text { AWAC }\end{array}$ & $x=400 m, y=940 m$ & See $8 \mathrm{~m}$ AWAC. & $1 \mathrm{hr}$. \\
\hline $\begin{array}{l}\text { Aquadopp3.5m } \\
\text { Aquadopp }\end{array}$ & $x=300 m, y=940 m$ & See $8 \mathrm{~m}$ AWAC. & $1 \mathrm{hr}$. \\
\hline Altimeters & various & Bed elevation. & irregular \\
\hline lidar & $x=7 m, y=940 m$ & $\begin{array}{l}\text { Run-up, surf-zone significant wave } \\
\text { height and mean water level. }\end{array}$ & $1 \mathrm{hr}$. \\
\hline
\end{tabular}




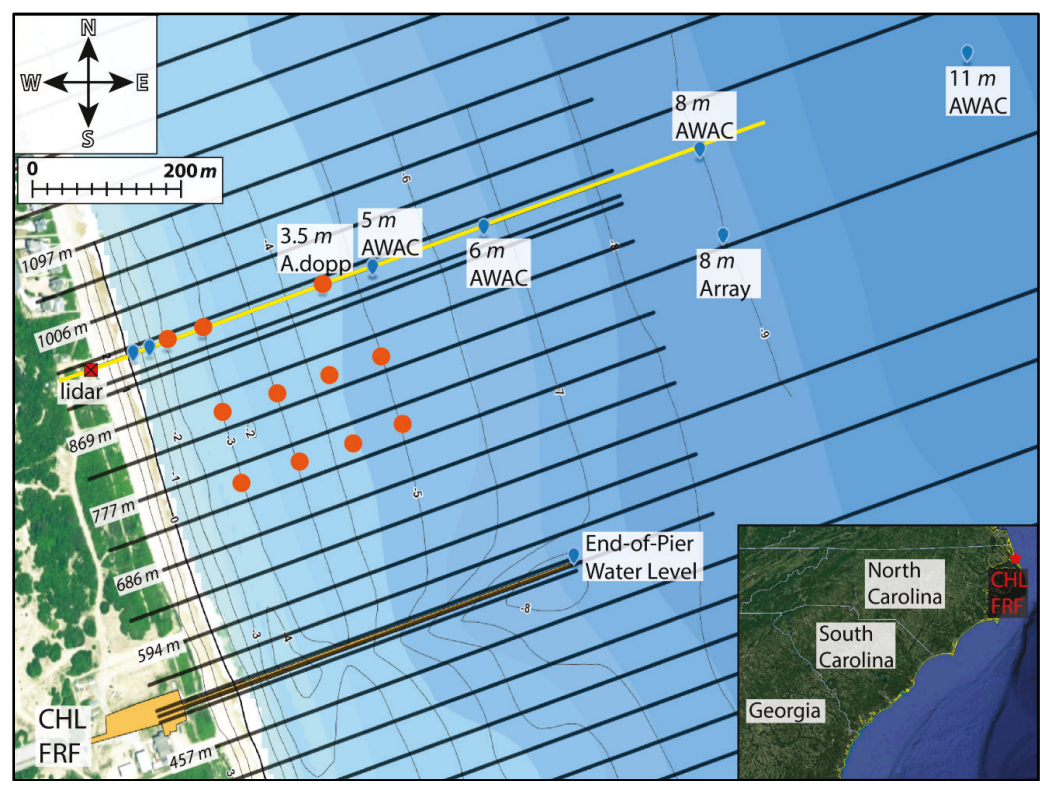

Figure 2. Map of the CHL FRF and gauge locations. General location courtesy of Google Earth. Altimeter locations shown with orange circles (note: the $3.5 \mathrm{~m}$ Aquadopp is co-located with an altimeter). Selected survey lines are labeled with their respective alongshore coordinates. Modeled transect is in yellow.

The data collected by these instruments are publicly available on a Thematic Real-time Environmental Distributed Data Services (THREDDS) server (www.chlthredds.erdc.dren.mil). Bathymetric surveys are conducted monthly along standardized transects (black lines and yellow line in Figure 2) utilizing a Lighter Amphibious Resupply Cargo or Coastal Research Amphibious Buggy (Birkemeier and Mason 1984). Spatial data are presented in a local cross $(x)$ and alongshore (y) coordinate system, with origin at $36.1776^{\circ} \mathrm{N}$ and $75.7497^{\circ} \mathrm{W}$ and a rotation of $17.7^{\circ}$ relative to true north (see Figure 2).

MODEL SETUP: The bathymetry profiles for the CMTB CSHORE model runs are obtained from the integrated bathymetry product, located on the CHL THREDDS server (Young et al. 2018). The integrated bathymetry product is an archive of DEMs that have been updated with the most recent bathymetric measurements. The single model transect is based on data located at the alongshore coordinate of $951 \mathrm{~m}$ (yellow line in Figure 2), the surveyed profile number located closest to the cross-shore array of gauges. The offshore model boundary begins at the cross-shore location of the $8 \mathrm{~m}$ Array or $6 \mathrm{~m} \mathrm{AWAC}$, depending on the availability of wave data, rounded to the nearest meter; the nodes are positive shoreward at $1 \mathrm{~m}$ intervals to the onshore boundary of the gridded survey product.

CSHORE is currently set up in three configurations, each run at a daily interval. The first utilizes a fixed bed in which the profile elevation is held constant for the duration of the simulation (FIXED). The second setup allows for the bed elevation to continuously evolve with time (MOBILE), and the final setup (MOBILE_RESET) evolves the bed but resets the bathymetry on the days after new survey data become available. The FIXED case is designed to test hydrodynamics with an appropriately accurate measured bathymetry. The immovable bed permits 
a simpler model/data comparison without the complexities of morphology change. The MOBILE case is designed as a full comparison to the morphology change predictions over long time scales whereas the MOBILE_RESET case addresses morphology change predictions between surveys. The general workflow of the CSHORE model in the CMTB framework is outlined below.

Data Retrieval. The first step in the CSHORE model is to autonomously retrieve the bathymetry and boundary condition data necessary from the THREDDS server. This process is performed by the getObs class in the CMTB python package getdatatestbed.py. Given a start date and assumed (or user-input) simulation duration, the script will search through the THREDDS server for the relevant data and return the information in a Python dictionary. Each type of data has a specific method (a class-specific function) to retrieve the information (e.g., getcurrents retrieves currents, getWaveSpec retrieves waves, getWL retrieves water level, getbathytransect retrieves bathymetry transects). Each method is capable of retrieving data from any appropriate CHL FRF gauge given the gauge name/ID number (Bak et al. 2017).

The required boundary condition data (Table 1) are retrieved for each model time-step spanning the full model duration. If the model version is set to FIXED, the initial bathymetry is from the most recent integrated bathymetry product; if the model is set to MOBILE, the code will search the THREDDS server for the results of the previous day's CSHORE model run and use the final evolved bathymetry from the previous run as the initial bathymetry for the start of the current run, effectively modeling the sea floor evolution in near real-time. MOBILE_RESET will use the results of the previous day's CSHORE model run as the initial bathymetry unless a new survey is discovered on the THREDDS server, in which case the updated survey becomes the initial bathymetry.

Input Data Manipulation and File Writing. Differences exist in convention between the required model inputs and the conventions established at the FRF; therefore, the input data are manipulated to fit the expected input of the CSHORE model, (i.e., (1) the CHL FRF reports significant wave height $\left(\mathrm{H}_{\mathrm{s}}\right)$ rather than $\mathrm{H}_{\mathrm{rms}}$ as required by CSHORE; (2) the CHL FRF wave angle convention is degrees clockwise from true north, rather than the counter-clockwise from shore-normal convention of CSHORE (see Figure 1); (3) the ocean current data are in East $\left(\mathrm{V}_{\mathrm{E}}\right)$ and North $\left(\mathrm{V}_{\mathrm{N}}\right)$ rather than cross-shore $(\mathrm{U})$ and alongshore $(\mathrm{V})$ as required by the model; (4) the local coordinate system is positive offshore as opposed to that of the model, requiring the origin at the offshore boundary). The CSHOREsimSetup function addresses these differences prior to writing the CSHORE input files. The bathymetry data are cropped at the model boundary (the $6 \mathrm{~m}$ AWAC or $8 \mathrm{~m}$ array), and the cross-shore coordinates of the cropped bathymetry are flipped such that $\mathrm{x}=0$ becomes the offshore boundary. The manipulated data are stored in a Python dictionary along with the other boundary condition data, such as model start time, duration, version, etc., then passed to the cshoreIO class method make_CSHORE_infile, which writes the data from the Python dictionary into a formatted text file read by the CSHORE model executable. The CSHORE model executable reads the input file, runs the model with the specified conditions, and outputs a series of output text files.

Output File Parsing and Post-Processing Routines. The makeCSHORE_ncdict function in the custom Python package CSHORE_analysis reads the CSHORE model output text files and stores them in a series of Python dictionaries using the cshoreIO class method load_CSHORE_results. The output data are parsed and post-processed to match those initial data 
conventions. In addition to the discrepancies between model convention and data formats already discussed, the mean velocity, standard deviation of the velocity, and the suspended/bedload sediment flux must be transformed from the model's cross-shore/alongshore coordinate system to the standard E/N coordinate system for mean current data. This is accomplished via the vectorRotation function given a pier angle of $71.8^{\circ}$ (the angle between true north and the CHL FRF pier; Figure 2). The makeCSHORE_ncdict collects all the model outputs (now in CHL FRF coordinate conventions) and stores them in a single Python dictionary that is passed to the makenc.py package function makenc_CSHORErun, which writes netCDF files in the file format conventions previously established at the FRF. This allows for easy archival data retrieval and facilitates in-depth data analysis.

Model Analysis. The final steps performed in the automated CMTB CSHORE workflow are to generate automated plots of the results and comparison data as well as performing basic statistical comparisons between the model and data. Comparison data include bed elevations from the altimeters, lidar runup, and wave heights and alongshore currents at the nearby wave gauges. If necessary (due to the specified model time-steps), the comparison data are interpolated onto the model results time-stamps. The CSHORE_plotLib.py Python package has functions to automatically generate comparison, and quality assurance/quality control (QA/QC) plots given a function-specific Python plotting dictionary:

1. $b c \_$plot generates plots of the boundary condition data used as model inputsfor QA/QC purposes.

2. obs_V_mod_bathy (see Figure 4) generates a scatter comparison plot and a spatial plot of bathymetry (e.g., initial bathymetry vs. final bathymetry), including the spatial variation of the model wave height on a separate $y$-axis. The volume change inside the $3 \mathrm{~m}$ and $8 \mathrm{~m}$ elevation contours, as well as statistical comparison information, are included in a subwindow of the figure. Comparison data from the altimeters and wave gages are included where available (Figure 2).

3. obs_V_mod_TS (Figure 5) generates a time-series and scatter plot of any two sets of timematched, time-series data (e.g., modeled runup to lidar-measured runup, model bed elevation to altimeter bed elevation) and includes statistical comparison information (see Bryant et al. 2016) in a sub-window of the figure.

4. mod_results generates a figure with three sub-windows containing cross-shore spatial plots of the model (1) wave height, (2) setup, and (3) bed elevation over the duration of the model run, including the standard deviation of those values; altimeter and wave gauge data are included for validation and QA/QC.

5. als_results generates a figure with two sub-windows of spatial comparison plots: (1) the model alongshore current and bathymetry (on separate $y$-axes) as a function of cross-shore position and (2) the model wave height and bathymetry (again on separate $y$-axes) as a function of cross-shore position. Altimeter bed elevations, wave gauge wave heights, and measured alongshore currents are included for validation.

EXAMPLE CMTB CSHORE RESULTS: The sample results from a CMTB CSHORE MOBILE version model run from 19 September 2015 to 1 October 2015 are shown in Figures 4 and 5. These dates were chosen due to the availability of (1) lidar comparison data, (2) forcing data from the $6 \mathrm{~m} \mathrm{AWAC}$, and (3) survey data taken shortly before the model start and end times. Figure 3 shows both wave height $\left(\mathrm{H}_{\mathrm{s}}\right)$ and mean wave direction $(\theta)$ at the $6 \mathrm{~m} \mathrm{AWAC} \mathrm{-} \mathrm{the} \mathrm{offshore}$ 
boundary of the model. The wave angle is measured clockwise from shore-normal. At the beginning of this time period, waves were coming from the south and below $1 \mathrm{~m}$. As the simulation progressed, wave heights increased to $3.5 \mathrm{~m}$, and the wave direction rotated more northerly with the passage of a small coastal storm.

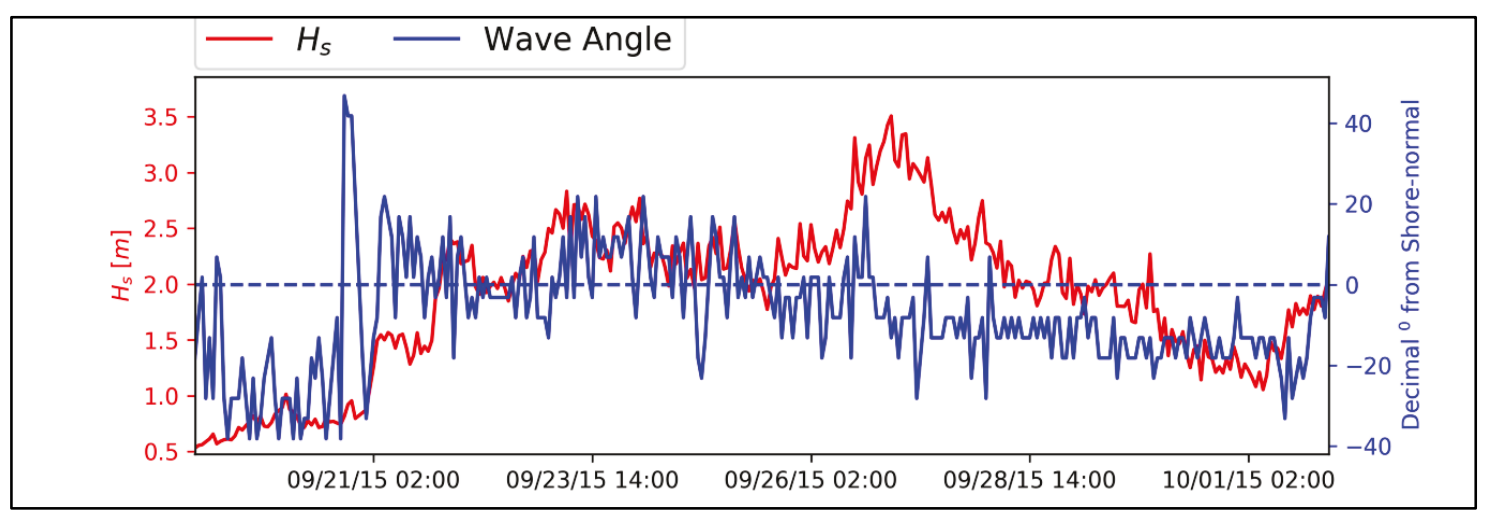

Figure 3. Significant wave height $\left(\mathrm{H}_{\mathrm{s}}\right)$ and wave angle $(\theta)$ at offshore boundary during model run.

Figure 4 shows a comparison among the initialization bathymetry (survey on 15 September 2015 - red dashed line), model predicted bathymetry at the conclusion of the model run (gold line), and the bathymetry survey during the last day of the model run (1 October 2015 - red solid line). The model reasonably estimates the offshore bathymetry profile at cross-shore positions greater than $325 \mathrm{~m}$ in the cross-shore but does not adequately simulate either the sandbar formation or beach slope shown by the 1 October 2015 survey. The modeled wave heights (green line in Figure 4) do display the behavior expected based on the bathymetry - slowly decreasing from offshore to onshore, briefly increasing immediately offshore of the position of the sandbar (in the model) and decreasing to zero onshore of the sandbar as the waves lose energy. 

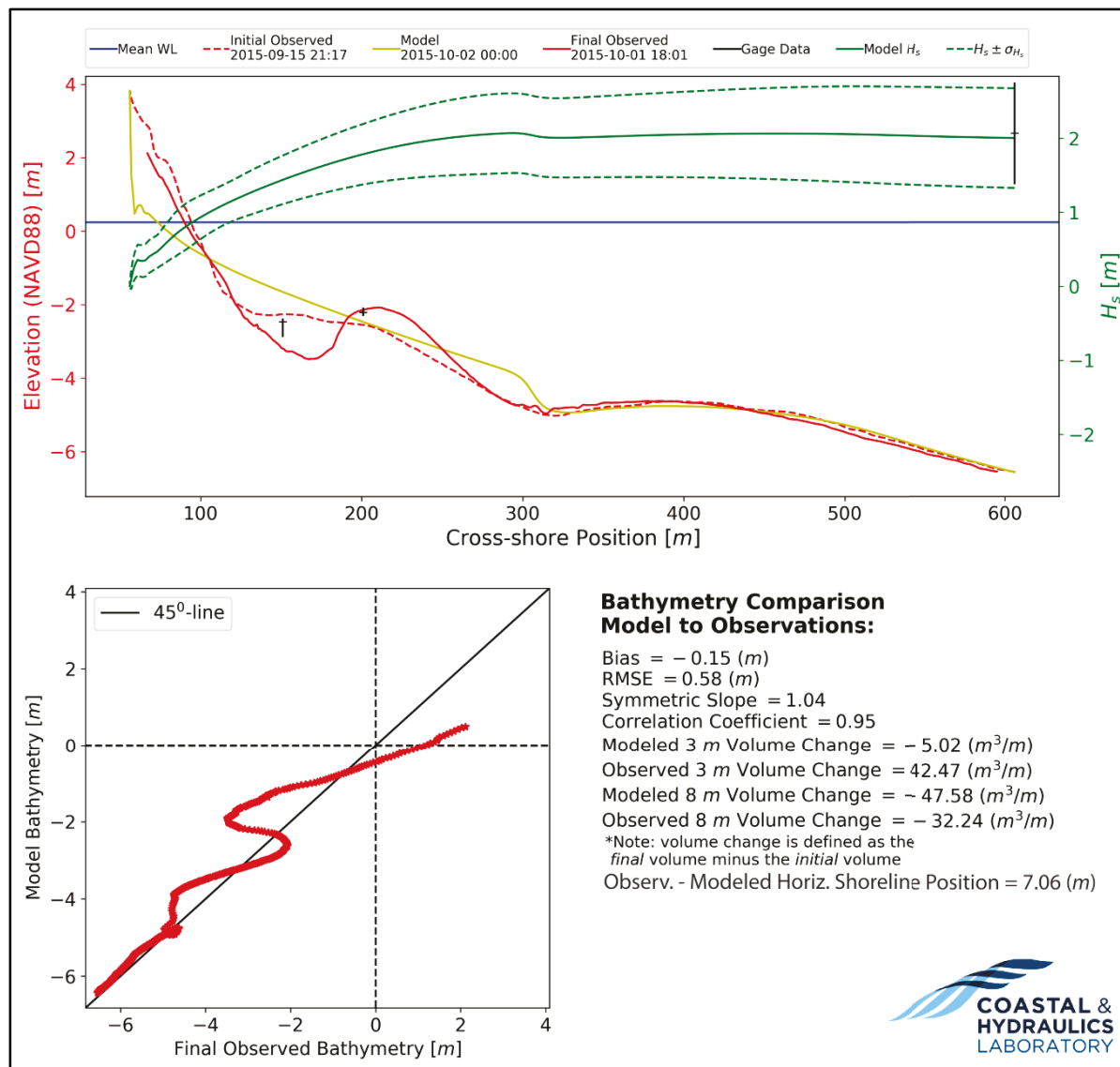

Bathymetry Comparison Model to Observations:

Bias $=-0.15(\mathrm{~m})$

Symmetric Slope $=1.04$

Correlation Coefficient $=0.95$

Modeled $3 \mathrm{~m}$ Volume Change $=-5.02\left(\mathrm{~m}^{3} / \mathrm{m}\right)$

Observed $3 \mathrm{~m}$ Volume Change $=42.47\left(\mathrm{~m}^{3} / \mathrm{m}\right)$

Modeled $8 \mathrm{~m}$ Volume Change $=-47.58\left(\mathrm{~m}^{3} / \mathrm{m}\right)$

Observed $8 \mathrm{~m}$ Volume Change $=-32.24\left(\mathrm{~m}^{3} / \mathrm{m}\right)$

*Note: volume change is defined as the

Observ. - Modeled Horiz. Shoreline Position $=7.06(\mathrm{~m})$

Figure 4. Comparison of the initial survey bathymetry, the bathymetry at the conclusion of the CSHORE model run to the bathymetry surveyed on the last day of the model run - including the elevation vs. crossshore position (top), model vs. observed elevations (bottom-left), and comparison statistics.

CSHORE predicts the $2 \%$ exceedance runup, defined as elevation that only $2 \%$ of the observed wave runup exceeds over a given sample. In Figure 5, modeled runup is compared to the runup measured by the dune lidar system. During this evaluation period, the model tended to underpredict the observed runup for smaller observed runup values (and lower wave conditions), but overpredicted the observed runup for observed runup values exceeding $2.75 \mathrm{~m}$ (and larger wave conditions). Nonetheless, based on the time-series, the model does appear to reasonably follow the general trends of the observed runup $\left(\mathrm{R}^{2}=0.82\right.$; see Figure 5 for additional comparison statistics). 


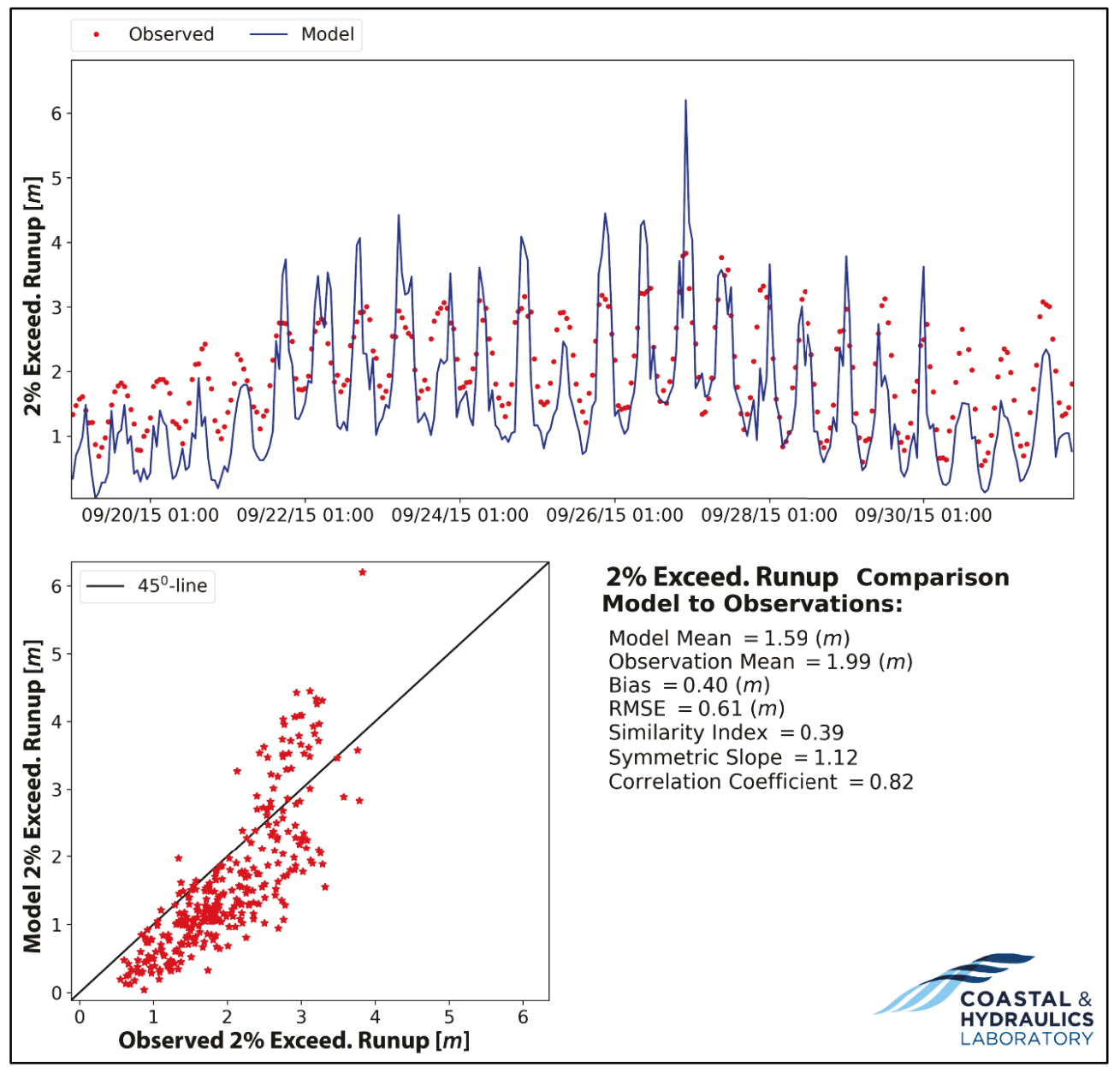

Figure 5. Comparison of the modeled CSHORE 2\% Exceedance Runup to the 2\% Exceedance Runup measured by the dune lidar, including the time-series (top), one-to-one plot (bottom-left) and statistics for a model run.

SUMMARY AND FUTURE DEVELOPMENT: The 1D (cross-shore) profile evolution model CSHORE has been incorporated into the CMTB. CSHORE is run daily with an hourly time-step and the results and QA/QC plots are autonomously generated. The CMTB framework allows easy integration of new models. As the CMTB project proceeds, new metrics and/or processes will be developed and integrated into the present methodology. CSHORE and other CMTB models will be examined to identify strengths and areas of potential improvement, either via tuning model parameters or developing new understanding of the underlying physical processes. The end goal of this effort is to guide and focus future research improving the numerical modeling capability of the USACE and the wider scientific community. 
ADDITIONAL INFORMATION: This Coastal and Hydraulics Engineering Technical Note (CHETN) was prepared as part of the USACE Coastal and Ocean Data System (CODS) program by Dr. David L. Young, Dr. A. Spicer Bak, and Dr. Bradley D. Johnson, U.S. Army Engineer Research and Development Center (ERDC), Coastal and Hydraulics Laboratory (CHL), Coastal Analysis and Observations Branch (COAB), Duck, NC. Questions pertaining to this CHETN may be directed to Dr. A. Spicer Bak (Spicer.Bak@usace.army.mil) or to the USACE CODS Program Manager, Dr. Jeffrey P. Waters.

This ERDC/CHL CHETN-IV-115 should be cited as follows:

Young, D. L., A. S. Bak, and B. Johnson. 2019. Initialization and Setup of the Coastal Model Test Bed: CSHORE. ERDC/CHL CHETN-IV-115. Vicksburg, MS: U.S. Army Engineer Research and Development Center. http://dx.doi.org/10.21079/11681/32387

\section{REFERENCES}

Bak, A. S., T. Hesser, J. Smith, and M. Bryant. 2017. Initialization and Setup of the Coastal Model Test Bed: STWAVE. ERDC/CHL CHETN-I-93. Vicksburg, MS: U.S. Army Engineer Research and Dvelopment Center.

Battjes, J. A., and M. J. F. Stive. 1985. Calibration and verification of a dissipation model for random breaking waves. Journal of Geophysical Research 90(C5):159-167.

Birkemeier, W. A., and C. Mason. 1984. The CRAB: A unique nearshore surveying vehicle. Journal of Surveying Engineering 110(1):1-7.

Brodie, K. L., B. Raubenheimer, S. Elgar, R. K. Slocum, and J. E. McNinch. 2015. Lidar and pressure measurements of inner-surfzone waves and setup. Journal of Atmospheric and Oceanic Technology 32(10):1945-1959.

Bryant, M. A., T. Hesser, and R. E. Jensen. 2016. Evaluation Statistics Computed for the Wave Information Studies (WIS). ERDC/CHL CHETN-I-91. Vicksburg, MS: U.S. Army Engineer Research and Development Center.

Dean, R. G., and R. A. Dalrymple. 1991. Water Wave Mechanics for Engineers and Scientists. Hackensack, NJ: World Scientific Publishing.

Hanson, J., H. Friebel, and K. Hathaway. 2009. Coastal wave energy dissipation: Observations and STWAVE-FP performance. In Proceedings, $11^{\text {th }}$ International Workshop on Wave Hindcasting and Forecasting \& $2^{\text {nd }}$ Coastal Hazards Symposium. Halifax, Nova Scotia, Canada.

Holman, R., and J. Stanley. 2007. The history and technical capabilities of ARGUS. Coastal Engineering 54(67):477-491.

IEEE. 1985. IEEE Standard for Binary Floating-Point Arithmatic. American National Standards Institute/Institute of Electrical and Electronics Engineers ANSI/IEEE Standard 754.

Johnson, B. D., N. Kobayashi, and M. B. Gravens. 2012. Cross-Shore Numerical Model CSHORE for Waves, Currents, Sediment Transport and Beach Profile Evolution. ERDC/CHL TR-12-22. Vicksburg, MS: U.S. Army Engineer Research and Development Center.

Kobayashi, N. 2013. Cross-Shore Numerical Model CSHORE 2013 for Sand Beaches and Coastal Structures. CACR Research Report CACR-13-01. Newark, DE: Center for Applied Coastal Research, Ocean Engineering Laboratory, University of Delaware. 
Kobayashi, N., and B. D. Johnson. 2001. Sand suspension, storage, advection, and settling in surf and swash zones. Journal of Geophysical Research 106 (9):363-376.

Kobayashi, N., A. Payo, and L. Schmied. 2008a. Cross-shore suspended sand and bedload transport on beaches. Journal of Geophysical Research 113(C07001). doi:10.1029/2007JC004203

Kobayashi, N., F. J. de los Santos, and P. G. Kearney. 2008b. Time-averaged probabilistic model for irregular wave runup on impermeable slopes. Journal of Waterway, Port, Coastal, and Ocean Engineering 116(6):708-726

Kobayashi, N., H. Zhao, and Y. Tega. 2005. Suspended sand transport in surf zones. Journal of Geophysical Research 110(C12009). doi:10.1029/2004JC002853

Madsen, O. S., and W. D. Grant. 1976. Quantitative description of sediment transport by waves. In Proceedings $15^{\text {th }}$ Coastal Engineering Conference. Reston, VA: ASCE, 1093-1112.

Massey, T., M. E. Anderson, J. M. Smith, J. Gomez, and R. Jones. 2011. STWAVE: Steady-State Spectral Wave Model User's Manual for STWAVE, Version 6.0. ERDC/CHL SR-11-1. Vicksburg, MS: U.S. Army Engineer Research and Development Center.

Ruessink, B., J. R. Miles, F. Feddersen, R. T. Guza, and S. Elgar. 2001. Modeling the alongshore current on barred beaches. Journal of Geophysical Research 106(C10)22:451-463.

Safak, I., J. H. List, J. C. Warner, and N. Kumar. 2017. Observations and 3D hydrodynamics-based modeling of decaldal-scale shoreline change along the Outer Banks, North Carolina. Coastal Engineering 120:78-92.

Sheremet, A., J. R. Davis, M. Tian, J. L. Hanson, and K. K. Hathaway. 2016. TRIADS: A phase-resolving model for nonlinear shoaling of directional wave spectra. Ocean Modelling 99:60-74.

Young, D. L., A. S. Bak, and M. F. Forte. 2018. Initialization and Setup of the Coastal Model Test Bed: Integrated Bathymetry. ERDC/CHL CHETN-IV-113. Vicksburg, MS: U.S. Army Engineer Research and Dvelopment Center.

NOTE: The contents of this technical note are not to be used for advertising, publication, or promotional purposes. Citation of trade names does not constitute an official endorsement or approval of the use of such products. 